I Universidade Nova de Lisboa, Centro Interdisciplinar de Ciências Sociais (Cicsnova) da Faculdade de Ciências Sociais e Humanas, Lisboa, Portugal rmocampos@yahoo.com.br

https://orcid.org/00oo-0003-4689-0I44
Ricardo Marnoto de Oliveira Campos'

\title{
JUVENTUDE E CULTURAS DE RUA HÍBRIDAS ${ }^{1}$
}

O espaço público urbano e a rua têm estado amplamente presentes na literatura que se dedica ao estudo da juventude. Da Escola de Chicago à Escola de Birmingham, passando, por muitos outros autores que se têm debruçado sobre as culturas e subculturas juvenis, a cidade, o espaço público urbano e a rua estão de alguma forma omnipresentes. De forma geral, o espaço público urbano corresponde a um espaço de sociabilidade e de criatividade, utilizado como palco para o desenvolvimento de uma série de práticas que se desenrolam fora da alçada das instituições e do olhar dos adultos. Daí que, em muitas situações, esse seja um terreno de autonomia que admite a criação de regras particulares, à margem dos normativos dominantes.

A generalização da internet e dos dispositivos móveis (tablets, smartphones, smartwatches etc.), que atinge também esse segmento etário, certamente teve um impacto na forma como o espaço é hoje vivido e representado. Apesar de a presença da internet ser razoavelmente transversal e generalizada, vários são os autores que apontam para o fato de as gerações mais jovens serem especialmente proficientes no que respeita ao uso das tecnologias digitais. Elas foram perfeitamente integradas num conjunto de dinâmicas sociais juvenis, tendo contribuído igualmente para criar novas práticas sociais.

Várias pesquisas têm demonstrado que, desde meados da primeira década do século XXI diversas atividades e expressões culturais tradicionalmente associadas ao espaço da rua se transferiram também para o domínio online. 
Parece haver consenso de que a internet não apenas deu origem a comunidades online, como transformou hábitos e vivências das diferentes culturas juvenis. Os estudiosos das culturas e subculturas juvenis não têm estado alheados da relevância da internet, como revela a literatura produzida nas últimas duas décadas (Bennett, 20I5b, 2004; Hodkinson, 2004; Williams, 2006; Wilson \& Atkinson, 2005; Campos, 2009, 20I 2; Campos \& Simões, 20I I; Simões \& Campos, 2017).

Neste artigo reflito sobre a relação entre as culturas juvenis, a rua e os circuitos digitais. Essas são as três dimensões teóricas e analíticas que servem de base à minha reflexão, tendo igualmente como suporte um conjunto de pesquisas em que estive envolvido nos últimos anos, que cruzam as áreas da juventude, das práticas culturais e criativas, bem como do ativismo.

\section{CULTURAS JUVENIS: DIFERENTES MODOS DE SER JOVEM}

A juventude é geralmente vista como um estádio de transição, uma passagem da infância para o estado adulto. Todavia, longe de definir unicamente uma etapa biológica a juventude é, acima de tudo, uma construção social, que adquire contornos singulares em função dos contextos históricos, sociais e culturais (Pais, I993; Feixa, 2006; Frith, I984). A noção de juventude aplica-se a um conjunto de indivíduos próximos em termos de idade biológica, mas que, acima de tudo, partilham uma série de características socioculturais que os distinguem da restante comunidade. Como refere Frith (I984: 2), a juventude "descreve aspectos da posição social das pessoas que são um efeito da sua idade biológica, mas não completamente determinados por ela. [...] a juventude não é simplesmente um grupo etário, mas a organização social de um grupo etário".

Associada à juventude, particularmente no contexto das sociedades mais ricas do hemisfério Norte, parece estar a ideia de dependência e ausência de responsabilidade. ${ }^{2}$ Os jovens encontram-se geralmente sob a alçada de diferentes instituições sociais (escola, família etc.), que se responsabilizam por sua sobrevivência e formação, fator que determina profundamente seus modos de vida, bem como as expectativas e imagens sociais que sobre eles recaem. Subalternidade e transitoriedade são, portanto, dois elementos centrais da condição social juvenil. Por conseguinte, a passagem ao estado adulto representa a transição para a independência, a responsabilidade, a aquisição de atributos que permitem maior controle sobre o quotidiano e os projetos de vida.

Se existe alguma homogeneidade na forma como olhamos para os jovens, quando partilham uma mesma condição social e um modo de vida juvenil, por outro lado, não poderemos esquecer a heterogeneidade que atravessa esse grupo (Pais, I993; Feixa \& Nofre, 20I2). A heterogeneidade deriva quer dos múltiplos contextos em que vivem os indivíduos, quer das diferentes opções, estilos e projetos de vida que eles abraçam. E é precisamente a partir dessa ideia de diversidade que surge o conceito de culturas juvenis. 
Nesse âmbito, é igualmente relevante introduzir o conceito de subcultura juvenil, que marcou um período decisivo da pesquisa sobre juventude e deu origem a uma corrente de estudos específica. A corrente subcultural, surgida na década de I970 no Reino Unido, chamava a atenção para a pluralidade de movimentos culturais e estilísticos juvenis, que se caracterizavam por um posicionamento algo periférico em face da cultura dominante (Hall \& Jefferson, I976; Hebdige, I979). As formas de resistência simbólica desenvolvidas por esses grupos serviram como modelo teórico para o entendimento de uma juventude paradoxal e antagônica. Essa corrente de estudos juvenis viria a ser largamente questionada e reavaliada, dando origem a um conjunto de posicionamentos conceitual e teoricamente distintos, que podemos situar brevemente como pertencendo às abordagens pós-subculturais (Muggleton \& Weinzierl, 2003; Bennett \& Kahn-Harris, 2004). Nesse caso, novos conceitos passaram a ser empregados, como os de tribo, neotribo, cena ou estilo de vida.

Neste artigo, todavia, emprego a expressão cultura juvenil, posto que não apenas é o mais abrangente, como também o menos conotado com uma corrente específica dos estudos juvenis. Interessa-me, por isso, destacar basicamente a heterogeneidade juvenil construída a partir das diferentes práticas que se constituem no campo do consumo e da produção estética e simbólica, nos territórios da sociabilidade e do lazer. Não devemos, no entanto, entender as culturas juvenis como reproduções algo passivas e miméticas daquilo que se encontra ao dispor no extenso mercado criado pelas indústrias culturais e pelos media. Algo que está muito presente nas diferentes concepções de culturas e subculturas juvenis diz respeito à capacidade de agência no campo cultural, associado à criatividade que pode assumir distintas expressões (música, indumentária, uso do corpo, práticas artísticas etc.).

A criatividade é, para muitos jovens uma questão de sobrevivência cultural, como admite Paul Willis (I990), que afirma serem o "trabalho simbólico" e a "criatividade simbólica" instrumentos vitais nessa busca constante por configurar os sentidos do Eu no mundo social. Importante reter, então, que a criatividade enquanto motor para o desenvolvimento de práticas expressivas juvenis, ocorre num determinado espaço. É, então, nesse contexto que certas culturas juvenis tomam a rua e o espaço público como terreno privilegiado de atuação, fazendo uso das oportunidades e dos meios que este lhes proporciona. Poderemos, então, pensar no espaço como um recurso que é usado criativamente, que é explorado pelos jovens com diferentes propósitos.

\section{A IMPORTÂNCIA DA RUA NAS CULTURAS JUVENIS}

A espacialidade é uma dimensão fulcral da vida dos jovens como defendem diferentes especialistas (Farrugia, 20I5; Farrugia \& Wood, 20I7; Glass, 20I 2; Robinson, 2000; Hall, Coffey \& Williamson, I999; Valentine, Skelton \& Chambers, I998; Woodman \& Leccardi, 20I5). Uma vez que os estudos juvenis têm priori- 
zado o contexto citadino, não é de estranhar que o espaço público urbano seja recorrentemente entendido como palco privilegiado para a manifestação das culturas juvenis. A cidade é lugar de descoberta não apenas no sentido geográfico, mas, essencialmente, no sentido simbólico e vivencial. A transição de uma infância resguardada pelo lar familiar e pela escola, baluartes de vigilância e proteção, é acompanhada por mais ampla exploração das geografias físicas e simbólicas em que os jovens podem, com alguma liberdade, construir novas relações e identidades. O antropólogo Carles Feixa (2003) sugere que ela é, em muitos sentidos, uma "cidade secreta", invisível ou resguardada do olhar dos adultos. Enclaves subterrâneos e liminares, não lugares, territórios notívagos ou marginais são frequentemente os espaços experimentados e apropriados, porque surgem nos interstícios da regulação e do ordenamento da vida citadina. A busca de autonomia passa, necessariamente, por encontrar outros referenciais simbólicos e culturais. Como afirmam Woodman e Leccardi (20 I5: 7 I3):

Os jovens são, muitas vezes, atraídos por um espaço público particular que parece menos convidativo, como um abrigo de ônibus, por exemplo, não apenas porque os outros espaços públicos são espaços "adultos" e, portanto, não há outro lugar para onde ir, mas também porque não é supervisionado, é aberto e acessível.

Daí que, por vezes, os jovens escolham territórios não adultos, que escapam à sua vigilância mas que também são esteticamente fabricados enquanto paisagens juvenilizadas, portando um conjunto de traços distintivos (graffiti, som de música, corpos jovens, indumentária e estilos visuais juvenis, adereços como skates, instrumentos de música etc.) (Feixa \& Porzio, 2008; Campos, 20I0, 20I Ia, 20I Ib). A dimensão da visibilidade e da paisagem ligada ao território é, a esse respeito, basilar enquanto campo para o exercício de criatividade e de distinção social. O espaço público é, assim, um espaço passível de ser construído com os pares, ao contrário do espaço familiar ou escolar, gerido e vigiado pelos adultos e, portanto, sob a alçada da autoridade. Há, por isso, uma certa sensação de conforto que se gera por identificação e pertença a um lugar que é partilhado com os semelhantes.

O espaço público da rua, porém, é também um terreno problemático. Esse espaço de autonomia, criatividade e, por vezes, de práticas desviantes, é olhado com desconfiança pelas instituições e autoridades, sempre prontas a reagir àquilo que possa desafiar as normas e convenções sociais. A juventude é vista como em risco permanente, situação que legitima a constante monotorização de que é alvo por diversas instâncias (Woodman \& Leccardi, 20I5). ${ }^{3}$ Daí que o espaço público seja um campo de tensão e conflito, em que se cruzam e colidem diferentes poderes e modos de conceber os usos do espaço.

Podemos sistematizar o papel do espaço público nas culturas juvenis envolvendo um conjunto de funções interligadas. Destaco quatro: sociabilidade; construção identitária; participação e cidadania; experimentação e criatividade. 
Em primeiro lugar, o espaço público é lugar de encontro frequente dos jovens, que a partir de redes de proximidade (bairro, escola) ou afinidade definem áreas geográficas de autonomia, em que podem sociabilizar para além dos espaços de consumo ou de controle das instituições (escola, família etc.). As redes de amigos ou a pertença a determinadas culturas juvenis é reforçada pelos momentos de encontro e de uso do espaço público urbano. Daí que as sociabilidades juvenis sejam indissociáveis de territórios que, com frequência, são apropriados e marcados simbolicamente pelos jovens como lugares de pertença, permitindo estabelecer linhas de segurança e conforto ontológico (Magnani, 2005). A delimitação de fronteiras geográficas tem também funções de diferenciação simbólica entre grupos e comunidades. Em muitos casos o uso do graffiti ou da pixação (Ley \& Cybriwsky, I974; Pereira, 201 2, 20I6) revela, precisamente, essa necessidade de demarcação territorial.

Em segundo lugar, diretamente associado com aquilo que referimos, encontra-se algo que é elementar para os jovens: a necessidade de pertença e de construção de identidades culturais que se revelem distintas, não necessariamente antagônicas, da cultura familiar. Esse processo passa pela diferenciação e autonomia identitária em face da família, mas também pela diferenciação entre os jovens. Ou seja, a heterogeneidade cultural típica da juventude expressa-se por múltiplas vertentes, sendo o espaço uma delas. Daí que certas "tribos", "subculturas" ou "cenas" não existam sem esse vínculo primordial com o espaço e a ocupação de determinados lugares.

Como terceiro ponto, podemos falar em participação num sentido que está, de alguma forma, ligado à ideia do "direito à cidade" (Lefebvre, I99I). Sendo os jovens definidos como indivíduos subalternos e dependentes, sob a alçada de um conjunto de instituições sociais que estabelecem balizas para ação social, sua capacidade de agência e participação é necessariamente limitada. Ora, no espaço público urbano os jovens exprimem formas de ser cidadão que não obedecem a hierarquias sociais e normativos de base adultocêntrica. A rua é um espaço verdadeiramente democrático. Nela surgem conflitos e negociações, dela emergem vozes insubordinadas, dela brotam sínteses culturais criativas que tanto ameaçam quanto alimentam a ordem natural das coisas. Daí que, como argumenta Machado Pais (2005: 57-58), a rua pode ser "reivindicada como um palco de cultura participativa" por parte dos jovens. Podemos falar em uma cidadania que representa "um movimento de rejeição da cidade planificada a favor da cidade praticada. De uma cidade que seja abrigo de manifestações culturais, não inevitavelmente institucionalizadas" (Pais, 2005: 60). Há, por isso, uma sensação de empoderamento na conquista e no domínio de certos territórios urbanos.

Por último, não podemos deixar de mencionar uma dimensão fulcral, a experimentação e criatividade. Não é por mera casualidade que muitos dos movimentos culturais e das novas propostas estéticas que despontaram no seio 
das culturas juvenis ao longo do século XX e início do XXI tenham ocorrido em ambiente urbano, no qual o espaço público adquire papel relevante. Esses são territórios propensos à incubação de modelos de regulação coletiva que escapam à normatividade dominante. Em muitos casos, as características do espaço e as matérias-primas que oferece tornam-se elementos capitais para o desenvolvimento de exercícios de índole criativa.

Fiz alusão ao papel relevante que a rua desempenha no contexto dos modos de vida juvenis. Todavia, falar em culturas juvenis na rua é diferente de falar em culturas juvenis de rua. Proponho uma definição de cultura de rua ampla, tal como entendida por Ross (2018: 8):

\begin{abstract}
Assim, eu defino a cultura de rua como as crenças, disposições, ideologias, regras informais, práticas, estilos, símbolos e valores associados, adotados e engajados por indivíduos e organizações que passam uma quantidade desproporcionada de tempo nas ruas dos grandes centros urbanos. Em muitos aspectos, a cultura de rua incorpora a noção de habitus de Bourdieu (1977), que explica como as pessoas percebem o mundo ao seu redor e como reagem, incluindo suas posturas corporais. A cultura de rua também é uma forma de comunicação tanto entre indivíduos dentro dessa cultura, como para pessoas de fora.
\end{abstract}

Segundo essa abordagem, as culturas de rua não se resumem ao espaço circunscrito da rua enquanto território, envolvendo uma dimensão imaterial e simbólica, funcionando enquanto signos culturais que transcendem o espaço. Desse modo, elas são motivo de inspiração para movimentos artísticos e estilos de vida e "uma fonte de ideias para mercadorias culturais que são compradas, vendidas, ouvidas, vistas etc. (por exemplo, música, comida, dança, literatura etc.)" (Ross, 20I8: 8). Logo, as culturas de rua também incorporam essa dimensão simbólica, que funciona geralmente em nível discursivo e ideológico, fundamentando um conjunto de valores, representações e modos de conduta. No meu entender, as culturas juvenis de rua são aquelas em que a rua desempenha um papel primordial em dois níveis: físico e simbólico.

No que respeita ao espaço físico, ele pode ser entendido como o território em que certas práticas culturais se desenrolam, tirando partido de um conjunto de constrangimentos, recursos e oportunidades proporcionados pelo contexto. Os constrangimentos envolvem as limitações físicas, inerentes ao território e ao seu edificado, mas também as sociais, relativas a sua ocupação, vigilância e regulação. Os recursos dizem respeito a um conjunto de elementos relativos às características do território, da materialidade e da mobilidade, que podem ser apropriadas e empregadas para o desenvolvimento de um conjunto específico de atividades. Por seu turno, as especificidades do espaço urbano e da rua oferecem uma gama de oportunidades para o desenvolvimento de atividades que não ocorreriam em outros contextos. As culturas juvenis associadas à prática do parkour, do skate, do graffiti, da street art ou do guerilla gardening só poderiam eclodir em circunstâncias em que a rua é recurso essencial a uma dinâmica 
que só se pode exprimir nesse espaço físico e que dialoga diretamente com suas características.

Há, no entanto, uma dimensão que é cada vez mais relevante no estudo das culturas de rua e que tem sido razoavelmente ignorada no debate. Pensar a apropriação do espaço urbano por parte dos jovens e de outros segmentos sociais implica refletir sobre os lugares, mas também sobre as mobilidades (Woodman \& Leccardi, 2015; Farrugia, 2015), num mundo cada vez mais interconectado e com recursos que permitem a mobilidade física ou virtual. Ou seja, não podemos pensar na geografia e na dimensão cultural e social de muitas das atividades individuais e coletivas em que estamos envolvidos sem analisar a capacidade de atravessar o espaço e o tempo que é proporcionada pela técnica, presente nos transportes, nos circuitos de comunicação etc. Logo, as fronteiras dos territórios podem ser mais ou menos rígidas, mas são atravessadas, cruzadas e sobrepostas. A mobilidade é um capital que interfere na constituição das culturas de rua e nas particularidades que elas assumem.

\section{CULTURAS JUVENIS HÍBRIDAS}

Afirmei que a juventude na sua versão ocidentalizada, nomeadamente nos países do hemisfério Norte, é geralmente representada como um grupo socioetário marcado pela transição da dependência e subalternidade (infância), para uma etapa da vida caracterizada por um conjunto de atributos sociais e legais que envolvem autonomia e responsabilidade, definindo o estado adulto (capacidade de voto, maioridade penal, ingresso no mercado de trabalho etc.). ${ }^{4}$ Se a juventude está razoavelmente desprovida de participação em algumas esferas da vida social (política e economia, por exemplo), em contrapartida, está enfaticamente vinculada às dimensões do lazer e do ócio, dos elementos estéticos e lúdicos. A imagem juvenil incide fortemente sobre esses elementos, convertendo-os em dimensões centrais para a definição dos estilos de vida e identidades dessa faixa etária (Pais, I993; Campos, 20I Ia, 20I Ib). O circuito global das indústrias culturais e dos meios de comunicação de massa, em expansão desde meados do século passado, tem sido uma fonte inesgotável de inspiração para grande parte das culturas juvenis. Essa não deixa de ser, porém, uma relação complexa que envolve dinâmicas em ambas as direções, uma vez que as indústrias culturais e os meios de comunicação também têm claramente absorvido e repercutido muitas das manifestações e criações juvenis.

Cada vez mais associada a essa dinâmica complexa, aparece a importância das tecnologias. A ubiquidade da internet e dos dispositivos digitais transformou por completo a forma como nos relacionamos com os outros e com o mundo que nos rodeia. A acelerada expansão dessas tecnologias, acompanhada pelas constantes transformações a que assistimos em termos dos sistemas de comunicação e interação digital atravessam variados domínios da nossa vida. Como múltiplas pesquisas têm revelado, há claras consequências no nível das sociabilidades e das 
formas de comunicação (Ito et al., 2008; Luders, 20I I), da participação cívica e política (Dahlgren, 2007; Loader, Vromen \& Xenos, 20I4), das produções e consumos culturais (Simões, 2010) ou da construção das identidades pessoais e culturais (Bennett, 2004, 20I5a, 20I5b; Robards \& Bennett, 20II).

A internet e as tecnologias digitais correspondem a um universo que oferece inúmeras possibilidades à expressão e comunicação dos mais jovens. As crianças e os jovens da atualidade nasceram na era da expansão da internet e da multiplicação dos dispositivos digitais. Prensky (200I) apelida a primeira geração que contactou com o mundo digital a dos nativos digitais, que se oporiam aos imigrantes digitais, com menor familiaridade e competências no emprego dessas tecnologias. De acordo com esse autor os nativos digitais seriam aqueles "que usam e estão rodeados por computadores, videogames, tocadores de música digital, câmeras de vídeo, telefones celulares e todos os outros brinquedos e ferramentas da era digital" (Prensky, 200I: I). De uma forma genérica essa expressão foi atribuída àqueles que nasceram nas décadas de I980 e I990 (Bennett, Maton \& Kervin, 2008), mas pode ser empregada para definir, igualmente, todos os que cresceram na era digital. Numa perspectiva próxima, Tapscott (I998) apelida-os de NET-geração. Vários autores, entretanto, têm questionado essa abordagem ou, pelo menos, a excessiva simplificação em que ela por vezes incorre (Buckingham, 2006; Bennett, Maton \& Kervin, 2008; Hargitai, 2010). Essa simplificação tende a ignorar a heterogeneidade de situações juvenis que decorrem da diversidade de acesso, mas também de uso dos próprios dispositivos digitais (DiMaggio et al., 2004; Hargittai, 2008, 2010).

Apesar do debate inquinado por alguma simplificação e recorrentes estereótipos, a pesquisa parece confirmar mais competências e conhecimento no manuseamento desses dispositivos tecnológicos por parte dos mais jovens, por comparação com seus pais. A esse propósito Livingstone (20I I: 357) refere o seguinte:

Para as crianças e jovens a internet parece ser o "seu" medium; eles são os primeiros a adotá-la, os mais experientes em media, os pioneiros na era cibernética, liderando em vez de ser liderados e, assim, invertendo o fosso geracional, à medida que ganham confiança e experiência.

O antropólogo Carles Feixa (20I4) emprega as expressões Geração @ e Geração \# para destacar a evolução que tem verificado na relação entre os jovens e a internet nas últimas décadas. A primeira corresponderia à geração da internet ou da rede, quando a segunda se caracteriza pela sua ligação à web social. Num texto mais recente, avança já com um conceito emergente, ainda por explorar envolvendo a web 3.0 e a noção de geração Blockchain (Feixa \& Weissböck, 20I9).

Cabe salientar que os jovens hoje correspondem a uma geração que nasceu não apenas na era digital, mas, essencialmente, na era da web 2.0 e das conexões móveis, ${ }^{5}$ sendo essas particularidades fundamentais para perceber a 
sua relação com as tecnologias. Ou seja, estamos tratando de indivíduos que participam claramente da sociedade 2.0 "formada por agrupamentos humanos que coexistem na e em rede, ampliam a ideia de desterritorialização do ciberespaço e traduzem novas formas de cultura que implicam (re)configurações do espaço social" (Amaral, 20ı6: 80).

A realidade revela-nos, então, um universo juvenil altamente conectado, em que as tecnologias são, cada vez mais, usadas para a criação e divulgação de conteúdos (Hargittai \& Walejko, 2008; Lenhart et al., 2007). Mas pensar a relevância da internet implica termos em conta os dispositivos concretos pelos quais ela é empregada, uma vez que estes são fundamentais para os modelos de utilização. Ou seja, é completamente diferente falar em internet quando ela dependia exclusivamente do PC com ligação fixa e no caso atual, em que se vulgarizaram os dispositivos móveis, bem como as redes de acesso wireless. Uma das mais relevantes transformações nesse nível diz respeito, precisamente, à banalização dos dispositivos móveis de acesso. Isso é particularmente saliente quando aludimos às culturas de rua, uma vez que o terreno originalmente associado aos primórdios da internet remete à ideia de sedentarismo e clausura. Falávamos de conexões fixas e espaços fechados, públicos ou privados (lar, escola, escritório, biblioteca etc.). O fato de a internet se tornar acessível no espaço público urbano, nomeadamente em situações de mobilidade, transfigura completamente a nossa experiência, abrindo caminho a um conjunto de novas práticas sociais.

O acesso a tecnologias móveis generalizou-se entre os jovens, chegando em alguns países ocidentais a uma taxa de penetração entre adolescentes que alcança perto de I00\% (Vanden Abeele, 20I6a). Por isso, desde o início das pesquisas sobre comunicações móveis, uma especial atenção tenha sido dedicada a essa categoria etária (Goggin, 2013, Vanden Abeele, 2016a, Mihailidis, 2014). Os estudos demonstram que as tecnologias móveis estão profundamente impregnadas em sua vida quotidiana: independentemente da localização, os jovens usam-nas para se manter em contato constante com as suas redes. Esse é um recurso em uso permanente, desde o momento em que acordam até que adormeçam. Daí que se fale de uma mobile youth culture (Vanden Abeele, 20I6b). Há uma assunção comum de que há algo distintivo na forma como os jovens e adolescentes se servem dos aparatos móveis. Isso se reflete na preferência por mensagens móveis, no uso de tecnologias móveis para autorrepresentação ou na criação de formas específicas de interação na comunicação móvel com amigos.

Os smartphones são, atualmente, dispositivos de mídia multifuncionais, que permitem conexão e comunicação, mas também produção, consumo e divulgação de conteúdos (imagem, som, texto). Desse modo, estamos perante um ecossistema digital multimidiático em que distintos dispositivos funcionam em rede. Os jovens parecem ter-se dado conta do potencial representado por essas tecnologias para a prossecução de suas atividades expressivas, incorpo- 
rando-as em seu quotidiano, mas inventando também novas formas de comunicar e de produzir conteúdos. Isso tem um impacto concreto no modo como hoje entendemos as culturas juvenis. Como refere Bennett (2004: I63), "as culturas juvenis podem ser vistas cada vez mais como culturas de 'ideias partilhadas', cujas interações acontecem não em espaços físicos, como na rua, no clube ou no festival, mas nos espaços virtuais facilitados pela internet".

É nesse contexto que gostaria de tratar de culturas juvenis híbridas. É sabido que o conceito de hibridismo é por demais utilizado no contexto das ciências sociais, nomeadamente por autores como Canclini (I989) ou Stuart Hall (2003), que abordam o hibridismo cultural no mundo contemporâneo. Os jovens, como propõem Feixa e Nilan (2009), participam mais claramente dos processos de hibridismo cultural ao fundir diversos referentes culturais e simbólicos. Massey (I998: I22-I23), por seu turno, afirma que "todas as culturas juvenis - e não apenas aqueles casos mais óbvios, como os filhos das diásporas - são culturas híbridas. Todas elas envolvem importação, adoção e adaptação ativa". Uma ontologia do hibridismo (Chadwick, Dennis \& Smith, 20I6) remete, então, a um conjunto de ideias, nomeadamente às fronteiras, aos fluxos e ao in-betweeness, rejeitando as dicotomias fáceis e dando relevo aos processos sociais e à sua complexidade.

Como refletir sobre essa questão num mundo mediático cada vez mais complexo? Vivemos, de acordo Chadwick, Dennis e Smith (20I6) num sistema híbrido de mídia, em que convivem e se cruzam lógicas e tecnologias novas e antigas. Mais do que isso, porém, vivemos na era da "cultura híbrida de media", como argumentam Lidgren, Dhalberg-Grundber e Johansson (20I4), caracterizada por uma situação em que é cada vez mais difícil sustentar uma clara divisão entre a realidade online e offline. Segundo esses autores esse hibridismo é uma condição da cultura contemporânea e corresponde, por um lado, à interseção permanente entre o mundo online e offline e, por outro lado, ao cruzamento e sobreposição entre "novos" e "velhos" meios de comunicação.

No caso que aqui nos ocupa a situação de hibridismo decorre dessa leitura. Considero hibridismo numa dupla vertente. Um primeiro sentido remete a uma simbiose entre corpo e tecnologia, entendendo que esta última se afirma cada vez mais como uma extensão do corpo humano. Nesse sentido, estaremos mais perto de uma noção algo ciborgue (Siqueiros \& Medeiros, 20I I) dos corpos juvenis contemporâneos, especialmente a partir do momento em que os dispositivos móveis se trivializaram. O segundo está relacionado com o hibridismo entre o material e o virtual, entre o domínio do território físico e das telas (ou écrans). Aquilo que acontece hoje é uma existência em que o mundo da presença física e da experiência sensorial da realidade encontra concomitantemente o seu duplo hipermidiático em múltiplos suportes.

Isso significa que, na atualidade, é praticamente impossível pensar na condição juvenil evitando essa questão relativa ao hibridismo que decorre da 
relação estreita e permanente que os sujeitos estabelecem com as tecnologias digitais e os seus conteúdos. Por outro lado, essa abordagem abre um conjunto de novas interrogações e possibilidades de conceitualização sobre aquilo que entendemos por "culturas de rua", posto que, de alguma forma, o território material da cidade deixa de ser o critério primordial para a sua definição. Ou seja, a dimensão da desterritorialização (e desmaterialização) das práticas sociais e culturais deve passar a ser entendida como elemento relevante quando falamos de culturas de rua.

\section{NAVEGANDO ENTRE A RUA E A TELA}

Após esse breve circuito de enquadramento do ponto de vista teórico adotado, detenho-me nas possíveis articulações entre a rua e a internet. Para essa discussão parto dos estudos empíricos por mim realizados ou de que participei em Portugal, bem como de uma revisão da literatura envolvendo pesquisas similares.

Gostaria de iniciar esta incursão invocando o caso que tenho pesquisado ao longo de cerca de uma década ${ }^{6}$ e que pode ser definido como uma (sub)cultura juvenil de rua: o graffiti (Campos, 2010). Outros pesquisadores têm vindo, também, a destacar o papel crescentemente importante da internet, quer para a cultura graffiti (Snyder, 2009; Diógenes, 20I5), quer para a street art (Bengtsen, 20I4). A hierarquização simbólica desse campo no período pré-digital era sustentada essencialmente pelos espaços informais da rua, em círculos sociais mais fechados. Atualmente o reconhecimento e o prestígio jogam-se, também, nas inúmeras plataformas digitais. Numa cultura em que a visibilidade é fundamental, importa desenvolver estratégias de disseminação do trabalho na rua, mas também é crucial utilizar as plataformas online para comunicação com determinados públicos (alargando a base social da audiência). Isso significa, em grande medida, maiores desterritorialização e globalização do graffiti que, via internet, converte as cidades e os bairros numa "aldeia global", para utilizar a expressão celebrizada por MacLuhan (I964). Desse modo, alargam-se as redes de contato social, dando visibilidade ao trabalho de graffiti-writers de diferentes continentes, como também estabelecendo facilmente elos de comunicação e de ação entre eles. Por seu turno, Bengtsen (20I4) avança com um dado interessante. Segundo esse pesquisador, a importância da internet no mundo da street art é tal, que a rua é, em muitos casos, apenas um meio para atingir um fim. O objetivo de muitos artistas é, simplesmente, a obtenção de boas imagens de suas obras para circular nas redes digitais, ampliando sua exposição pública.

Logo, a cidade virtual do graffiti é constituída por múltiplos fragmentos imagéticos e imaginários que se sobrepõem, e cuja ligação ao território é intrincada. O mais curioso, no caso do graffiti, é o fato de tornar visível (e acessível) uma cidade subterrânea e, por vezes, invisível. As invisibilidades urbanas (Campos, 20I7) são, assim, transportadas para uma esfera pública digital. Os milhares de vídeos disponíveis no YouTube sobre missões de graffiti ilegal em 
trens, por exemplo, permitem aceder a uma realidade muito pouco visível e perigosa. Ou seja, há uma realidade presente na cidade, raramente observável, que passa a fazer parte dessa fabricada cidade virtual do graffiti. Na internet lidamos com lógicas de impacto da informação completamente diferentes das referentes à realidade offline. Logo, podemos assumir que a centralidade e a imagem dos lugares dependem de critérios e estratégias de disseminação singulares, a que corresponde uma particular hierarquização simbólica dos lugares, alimentada por tweets, shares, comments, likes etc.

Outras pesquisas em que estive envolvido revelam algo parecido.7 Entrevistas realizadas com jovens que praticavam jerk ${ }^{8}$ (Campos, 20 I Ib) na área metropolitana de Lisboa, há cerca de dez anos, já desvendavam a importância que as tecnologias e mídias digitais assumiam para sua prática, servindo para adquirir visibilidade e fomentar a competição entre diferentes grupos. Os vídeos, filmados na rua, eram posteriormente colocados em plataformas digitais. A rua e o espaço público ganhavam protagonismo enquanto cenários para performances claramente desenhadas para funcionar na tela e ser difundida pelas redes digitais. Isso se verificou também no caso de jovens rappers amadores entrevistados no âmbito do projeto (Campos \& Simões, 20I I). Nesse caso as tecnologias digitais serviam diferentes propósitos no nível de produção cultural (música e videoclips), da divulgação e da aquisição de estatuto no meio. Um tipo de atividade geralmente territorializado, ligado à vida de bairro, adquire, assim, via internet, outra dimensão. Curiosa é, ainda, a capacidade de produção audiovisual que essas ferramentas abrem, havendo atualmente dezenas de vídeos elaborados de forma amadora ou semiprofissional disponíveis nas plataformas digitais sendo que, inevitavelmente, o meio urbano e nomeadamente os bairros são cenários recorrentes dessas produções (Aderaldo \& Raposo, 20I6; Campos \& Simões, 20I I). Outros estudos empíricos localizados em Portugal poderiam ser mencionados, no que se refere a práticas expressivas juvenis associadas à música ou dança, como o kuduro (Marcon, Sedano \& Raposo, 20I8; Marcon, 2013) ou ao hip-hop (Simões, 2010)

Em outro contexto, que remete ao ativismo e à participação política dos jovens, um estudo desenvolvido recentemente ${ }^{9}$ revela tendências iguais, verificando-se clara articulação entre a rua e os meios digitais (Campos, Simões \& Pereira, 20I8). Nesse caso os meios de comunicação digitais são úteis não apenas para divulgar e mobilizar as pessoas, mas também são intervenientes diretos nos acontecimentos de rua, servindo, por exemplo, para filmá-los a fim de os relatar. A pesquisa efetuada apenas confirma aquilo que foi observado em outros contextos recentes de maior turbulência política, na Europa e EUA (Loader, Vromen \& Xenos, 20I4; Fernandez-Planells, Figueras-Maz \& Feixa, 20I4) ou no Brasil (Recuero et al., 20I5; Rabin \& Bacich, 20I8).

Essas pesquisas permitem ilações semelhantes. Em virtude de interesses e práticas específicos, os jovens participam de comunidades virtuais que con- 
tribuem para a construção coletiva de significados, de conteúdos e redes, promovendo uma certa imagem da cidade e do espaço público urbano.

De acordo com a proposta teórica discutida e com as pesquisas realizadas, concebo a articulação entre a rua, a tecnologia digital e a internet, em dois níveis. Num primeiro nível, quando os dispositivos digitais e a internet servem enquanto recursos que interferem diretamente no espaço ou na forma como agimos sobre ele. Há estudos, por exemplo, que relacionam a posse de celulares com a exploração da cidade e do seu território (Leyshon, DiGiovanna \& Holcomb, 20I3). O celular confere mais segurança na descoberta da cidade, uma vez que permite contato imediato e constante com familiares e amigos, bem como dispõe de um conjunto de ferramentas que facultam uma navegação de forma controlada pelo ambiente urbano (GPS, Google maps etc.). Esses instrumentos permitem localizar facilmente um conjunto de elementos (pessoas ou recursos urbanos de diversas ordens). Por outro lado, o emprego de várias plataformas e aplicações existentes na web é fundamental para uma exploração e descoberta das cidades, das múltiplas ofertas e dos recursos disponíveis (restaurantes, bares, salas de concertos, estádios, rede de transportes etc.), desse modo consentindo uma gestão estratégica das mobilidades e dos diferentes tipos de atividades citadinas. Como afirmam Leyshon, DiGiovanna e Holcomb (2013: 601):

Uma leitura de nossa pesquisa parece sugerir que a terra incognita é agora apenas um conceito imaginário. Com um telefone móvel, a exploração dos lugares tornase simplesmente uma função de poder acessar dados, incluindo como viajar de e para um destino e locais de interesse. Isso parece sugerir que tudo o que precisamos saber sobre lugares já existe.

Ainda nesse domínio, não podemos ignorar a capacidade que os media digitais possuem na mobilização de pessoas e na criação de iniciativas no espaço público, de forma inusitada, informal e massiva. Isso dá origem a fenômenos novos como as flash mobs, que revelam bem até que ponto existem interseção e interação entre o espaço físico e as tecnologias de comunicação digital (Molnár, 20I4). Outros exemplos recentes do impacto que estes meios podem ter no espaço e na sua transformação, através da mobilização massiva de pessoas com um propósito comum, são os que remetem, como vimos, ao período politicamente mais conturbado da chamada primavera árabe, do movimento occupy ou da contestação às políticas de austeridade em alguns países europeus. Como diversos estudos indicaram as tecnologias digitais incentivaram a criação de fenômenos de natureza viral que tiveram consequências nos protestos e mobilizações políticas que se seguiram nas ruas de muitas cidades.

Num segundo nível, essa articulação pode ser concebida em outra direção, quando os dispositivos digitais fabricam uma realidade paralela de índole digital. Ou seja, quando geram no ciberespaço um conjunto de conteúdos (imagens, textos etc.) que, de alguma forma, se reportam a ações, episódios, paisagens etc. presentes ou ocorridos no espaço urbano. Essa desvinculação espa- 
çotemporal viabilizada pelos meios digitais reconfigura a experiência urbana, beneficiando a fabricação de distintos imaginários e narrativas sobre a cidade. Alguns autores têm apontado a relevância que os dispositivos de geolocalização associados às redes sociais digitais assumem no nível das sociabilidades e da construção de identidades individuais e colectivas (Schwartz \& Halegoua, 20 I5; Sutko \& De Souza e Silva, 20I I). Nesse contexto e colocando a ênfase na dimensão espacial, Schwartz e Halegoua (20I5: I644) propõem o conceito de spatial-self como "uma variedade de instâncias (online e offline) nas quais os indivíduos documentam, arquivam e exibem a sua experiência e/ou mobilidade no espaço e no lugar para representar ou 'performatizar' aspectos da sua identidade para outras pessoas". Estão em causa, nesse caso, a agência individual e a capacidade performativa mobilizadas na partilha de fragmentos da realidade vivida nos lugares, no sentido da construção de uma determinada versão do Eu. Nesse contexto o espaço físico assume relevância enquanto símbolo que transporta um conjunto de conotações. Logo, poderemos conceber a existência de uma espécie de cidade imagética e cibernética, que se reproduz e circula por via digital, produzida coletivamente por múltiplos indivíduos que vão alimentando incessantemente essa rede e que, por seu turno, sorvem a informação nela contida.

Nesse sentido, as tecnologias móveis passam a ser mais um recurso ao dispor dos jovens para ser usado no espaço público articulando-se, então, com outros recursos. A produção de imagens e conteúdos audiovisuais talvez seja a mais relevante nesse campo, por participar de nossas vivências mundanas. ${ }^{\text {Io }}$ A internet abriu caminho à multiplicação dos canais de propagação de imagens, a uma velocidade nunca vista. YouTube, Vimeo, Instagram, Flickr etc. tornaramse vias alternativas aos tradicionais circuitos de construção e consumo de imagens. Nesse contexto, como afirma Muller (2008: I02), a produção audiovisual "privatizou-se enquanto a disseminação se globalizou". Esses são instrumentos poderosos para o desenvolvimento da "criatividade vernacular" (Burgess \& Green, 2009) e da "cultura participativa" (Jenkins, 2006). Estamos, portanto, num novo mundo, no qual a fronteira entre os amadores e profissionais do audiovisual se torna cada vez mais turva. As culturas de rua não são, então, indiferentes a essa nova capacidade de visualização, como sustentam Pedram Dibazar e Judith Naeff (2018: 10):

os materiais visuais digitais integraram-se na experiência corpórea da rua contemporânea, uma vez que a pessoa a atravessa equipada com dispositivos smart. [...] Ao caminhar pela cidade com smartphones na mão, simultaneamente espacializamos os fluxos de dados virtuais, visualizando-os nas telas do telefone e visualizamos o espaço criando diferentes tipos de imagens - como fotografias, mapas e vídeos - disseminando-as online por meio de vários aplicativos. 


\section{CONCLUSÃO}

A ubiquidade da internet e dos dispositivos digitais demanda conexão constante, fazendo pouco sentido hoje estabelecer cisão entre os mundos offline e online. Na verdade, a nossa condição é cada vez mais de natureza híbrida, em que os corpos se confundem com as tecnologias, em que o material se articula com o virtual. Desse modo, falar hoje em práticas sociais que ocorrem num determinado espaço físico implica tratar da experiência concreta da imersão no território, mas também em outra realidade, que ganha expressão nos diversos circuitos e telas digitais e que interfere diretamente na forma como vivenciamos o espaço físico.

Há, certamente, novas práticas sociais que decorrem da presença constante desses dispositivos, como as que derivam da possibilidade de registar visualmente por fotografias e vídeos o nosso quotidiano, sendo a banalização da selfie um exemplo paradigmático dessa situação. Outras derivam da capacidade de geolocalização, da conexão permanente com um determinado círculo social ou da possibilidade de colocar rapidamente em circulação mediante vários canais um conjunto de mensagens. Poderíamos, ainda, referir a capacidade de criar ajuntamentos de pessoas no espaço físico a partir de mensagens de índole viral, que se propagam rapidamente. Seria difícil enunciar as múltiplas oportunidades abertas pelos circuitos digitais e pelas tecnologias móveis.

Os jovens são, como vimos, especialmente proficientes e criativos no uso das diferentes tecnologias e na produção de conteúdos digitais. Esse é um elemento fundamental para a construção de identidades pessoais e culturais, para a comunicação e expressão dos jovens, individualmente ou em grupo. Como tal, eles estão na vanguarda da invenção de novos usos para as tecnologias digitais, na sua adaptação aos contextos vividos e na fabricação de novas formas de expressão. São eles que registam em vídeo missões arriscadas de graffiti em metrôs e trens, que organizam flashmobs na rua ou produzem videoclips de dança nos bairros periféricos das cidades. Daí que as culturas juvenis de rua, na contemporaneidade, tenham necessariamente de integrar algo que pode ser já considerado uma extensão tecnológica do nosso ser: o smartphone. Essa tecnologia condensa uma multiplicidade de funções, servindo como exemplo paradigmático do potencial aberto pela internet.

Essa condição contemporânea tem, obviamente, consequências para a forma como representamos e nos apropriamos do espaço. A cidade material serve de inspiração à construção de uma cidade digital de natureza fragmentada, fruto de um conjunto de conteúdos produzidos e introduzidos no circuito por uma rede incomensurável de utilizadores. Mediascapes e ideoscapes, como denominou Appadurai (I996), são, atualmente, fortemente produzidos e mobilizados via mídias digitais, o que significa que correspondem a cenários amalgamados, em que convivem amadores e profissionais, lógicas periféricas e mainstream. 
O fato de a internet e os meios de comunicação digitais existirem e permitirem a construção dessas ruas, bairros e cidades digitais não significa que eles subsistam sem vínculo com o mundo offline e o território concreto. $\mathrm{O}$ que existe é, precisamente, um vai e vem entre o online e o offline, um sistema híbrido e complexo de retroalimentação. Aquilo que é visionado e consumido via internet tem impacto direto na rua, nas culturas de rua. Influi num conjunto de representações, de disposições, de práticas e de redes sociais que, por sua vez, dá origem a novos conteúdos, comunicações e mensagens por via digital. Ou seja, a principal conclusão que gostaria de destacar é a de que pensar nas culturas juvenis de rua, no século XXI, implica, necessariamente, pensar os dispositivos digitais e a forma como eles interferem em suas dinâmicas.

Recebido em I7/I/20I9 | Revisto em I6/4/20I9 | Aprovado em 28/8/20I9

Ricardo Marnoto de Oliveira Campos é mestre em sociologia e doutor em antropologia visual. Pesquisador integrado ao Centro

Interdisciplinar de Ciências Sociais da Faculdade de Ciências Sociais e Humanas e professor convidado da Universidade Aberta. Membro fundador e cocoordenador da Rede Luso-Brasileira de pesquisa em Artes e Intervenções Urbanas (Raiu), coordenador adjunto do GT de Cultura Visual da Associação Portuguesa de Ciências da Comunicação (Sopcom) e coeditor da revista internacional Cadernos de Arte \& Antropologia. Coordena os projetos Artcitizenship - Young people and the arts of citizenship: activism, participatory culture and creative practices (20I9-202I) e TransUrbArts - Emergent Urban Arts is Lisbon and São Paulo (2016-2020), ambos com apoio financeiro da FCT/MCTES. 


\section{NOTAS}

I Este artigo é desenvolvido no âmbito das atividades do projeto de investigação "Juventude e as artes da cidadania: práticas criativas, cultura participativa e ativismo", financiado pela Fundação para a Ciência e Tecnologia (PTDC/SOC -SOC/28655/2017).

2 Sabemos, todavia, que essa é uma imagem socialmente construída, homogeneizadora, que tende a obscurecer um mundo socialmente muito diverso e desigual. A realidade vivida pelos jovens diversifica-se bastante em função de um conjunto de variáveis estruturais que remetem, por exemplo, a classe social, etnia ou gênero. A esse respeito as diferenças entre juventude urbana e rural também devem aqui ser salientadas. Não devemos ignorar tampouco que a literatura acadêmica de referência se dirige a um contexto geográfico e sociocultural muito circunscrito, pelo que não deixa de promover uma imagem etnocêntrica da juventude, esquecendo a pluralidade de mundos juvenis no planeta.

3 Essa questão está ligada à ambivalência que geralmente rodeia a juventude, ora associada a uma fase problemática que origina comportamentos de risco (drogas, álcool, violência, sexualidade etc.), ora representando aquilo que é mais valorizado na nossa sociedade (saúde, energia, felicidade, sonho etc.).

4 No entanto, é de referir que as transições para o mundo adulto são cada vez mais incertas e flutuantes, como diversos autores têm apontado (Guerreiro \& Abrantes, 2005; Ferreira \& Nunes, 2010).

5 O termo web 2.0 refere-se a um conjunto de transformações tecnológicas que favorece a transformação da internet numa plataforma social, conferindo maior capacidade de participação e interacção ao utilizador comum. Este é, porém, um termo controverso e alvo de várias críticas por parte da comunidade acadêmica (Amaral, 20I6).

6 No âmbito do projeto de doutoramento, mas com diversos prolongamentos, incluindo o projeto que atualmente coordeno intitulado TransUrbArts (IF/OI592/20I5), sobre a arte urbana em Lisboa e São Paulo. Esta última é uma pesquisa de natureza qualitativa, envolvendo trabalho de 
campo etnográfico e entrevistas aprofundadas com diferentes atores do campo da arte urbana.

7 Nomeadamente o projeto internacional "Digital Inclusion and Participation in Portugal and USA" (2009-20II), que envolveu diversas metodologias de pesquisa, quantitativas e qualitativas, com amostras diferenciadas em função de gênero, classe social, idade, origem etc. Nele desenvolvi pesquisa sobre jovens, tendo entrevistado rappers, MC's ou jovens que se dedicavam à dança de rua jerk.

8 Jerk ou jerkin' é uma dança de rua surgida nos anos 2000 em Los Angeles, claramente influenciada pelo hip-hop e break-dance.

9 Projeto "Networked Youth Activism: Digital Media, Social Movements and Participatory Culture among Young Activists", financiado pela Fundação para a Ciência e Tecnologia (EXPL/IVC-COM/2I9I/20I3), que envolveu pesquisa qualitativa online e offline, com entrevistas a cerca de 30 jovens ativistas.

Io A esse respeito a selfie talvez represente o paradigma dessa nova condição.

\section{REFERÊNCIAS BIBLIOGRÁFICAS}

Aderaldo, Guilhermo \& Raposo, Otávio. (2016). Deslocando fronteiras. Horizontes Antropológicos, 45, p. 279-305.

Amaral, Inês. (2016). Redes sociais na internet: sociabilidades emergentes. Covilhã: Editora LabCom.IFP.

Appadurai, Arjun. (1996). Modernity at large: cultural dimensions of globalization. Minneapolis/London: University of Minnesota Press.

Bengtsen, Peter. (20I4). The street art world. Lund: Almendros de Granada Press.

Bennett, Andy. (2015a). 'Speaking of youth culture': a critical analysis of contemporary youth cultural practice. In: Woodman, Dan \& Bennett, Andy (orgs.). Youth cultures, transitions, and generations. Bridging the gap in youth research. New York: Palgrave Macmillan, p.42-55.

Bennett, Andy. (20I5b). Youth and play: identity, politics, and lifestyle. In: Wyn, Johanna. \& Cahill, Helen (orgs.). 
Handbook of children and youth studies. Singapore/Heidelberg/New York/Dordrecht/London: Springer, p. 775-788.

Bennett, Andy. (2004). Virtual subculture? Youth, identity and the internet. In: Bennett, Andy \& Kahn-Harris, Keith (orgs.). After subculture: critical studies in contemporary youth culture. Basingstoke: Palgrave MacMillan, p. I62-172.

Bennett, Andy \& Kahn-Harris, Keith (orgs.). (2004). After subculture. Critical studies in contemporary youth cultures. New York: Palgrave-Macmillan.

Bennett, Sue; Maton, Karl \& Kervin, Lisa. (2008). The 'digital natives' debate: a critical review of the evidence. British Journal of Educational Technology, 39/5, p. 775-786.

Bourdieu, Pierre. (1977). Outline of a theory of practice. Cambridge: Cambridge University Press.

Buckingham, David. (2006). 'Is there a digital generation?'. In: Buckingham David \& Willett, Rebekah (orgs.). Digital generations. Mahwah: Lawrence Erlbaum Associates, p. I-I3. Burgess, Jean \& Green, Joshua. (2009). YouTube. Online video and participatory culture. Cambridge: Polity.

Campos, Ricardo. (2017). On urban (in)visibilities. In: Hannigan, John \& Richards, Greg (eds.). The Sage handbook of new urban studies. Los Angeles/London/New Delhi/Singapore/Washington DC/Melbourne: Sage Publications, p. 232-249.

Campos, Ricardo. (2012). A pixelização dos muros: graffiti urbano, tecnologias digitais e cultura visual contemporânea. Revista Famecos: midia, cultura e tecnologia, I9/2, 543-566.

Campos, Ricardo. (20IIa). Identidade, imagem e representação na metrópole. In: Campos, Ricardo; Brighenti, Andrea Mubi \& Spinelli, Luciano. (orgs.) Uma cidade de imagens. Produção e consumo visual na cidade. Lisboa: Mundos Sociais, p. 15-30.

Campos, Ricardo. (20I Ib). A imagem digital como forma de comunicação e produção cultural juvenil na metrópole. Anais do XI Congresso Luso-Afro-Brasileiro. Disponível em: https://www.academia.edu/977640/A_IMAGEM_DIGITAL_COMO_FORMA_DE_COMUNICA\%C3\% 87\%C3\%83O _E_PRODU\%C3\%87\%C3\%83O_CULTURAL_JUVENIL_NA_ METR\%C3\%93POLE. Acesso em i2 jul. 2020. 
Campos, Ricardo. (2010). Por que pintamos a cidade? Uma abordagem etnográfica ao graffiti urbano. Lisboa: Fim de Século.

Campos, Ricardo. (2009). Movimentos da imagem no graffiti. Das ruas da cidade para os circuitos digitais. In: Carmo, Renato do \& Simões, José. A produção das mobilidades. Redes, espacialidades e trajectos. Lisboa: Imprensa de Ciências Sociais, p. 9I-II2.

Campos, Ricardo \& Simões, José. (20II). Participação e inclusão digital nas margens: uma abordagem exploratória das práticas de culturais de jovens afro-descendentes. O caso do rap negro. Media \& Jornalismo, I9, p. II7-I33.

Campos, Ricardo; Simões, José Alberto \& Pereira, Inês. (20I8). Digital media, youth practices and representations of recent activism in Portugal. Communications - The European Journal of Communication Research, 43/4, p. 489-507.

Canclini, Nestor G. (1989). Culturas híbridas. Ciudad de México: Grijalbo.

Dennis, James William; Chadwick, Andrew \& Smith, Amy P. (20I6). Politics in the age of hybrid media: power, systems, and media logics. In: Bruns, Axel et al. (eds.). The Routledge Companion to social media and politics. New York: Routledge, p. 7-22.

Dahlgren, Péter. (2007). Young citizens and new media. Learning for democratic participation. London: Routledge.

Dibazar, Pedram \& Naeff, Judith. (2018). Introduction: Visualizing the street. In: Dibazar, Pedram \& Judith Naeff (orgs.). Visualizing the street. New practices of documenting, navigating and imagining the city. Amsterdam: Amsterdam University Press, p. 9-26.

DiMaggio, Paul et al. (2004). Digital inequality: from unequal access to differentiated use. In: Neckerman, Kathryn (ed.). Social inequality. New York: Russell Sage Foundation, p. 355-400.

Diógenes, Glória. (20I5). Artes e intervenções urbanas entre esferas materiais e digitais: tensões legal-ilegal. Análise Social, 217, p. 682-707.

Farrugia, David. (2015). Space and place in studies of childhood and youth. In: Wyn, Johanna \& Cahill, Helen (orgs.). 
Handbook of children and youth studies. Singapore/Heidelberg/New York/Dordrecht/London: Springer, p. 609-624. Farrugia, David \& Wood, Bronwyn E. (2017). Youth and spatiality: towards interdisciplinarity in youth studies. Young, 25/3, p. 209-2I8.

Feixa, Carles. (20I4). De la generación @ a la \# generación: la juventud en la era digital. Barcelona: NED.

Feixa, Carles. (2006). De jóvenes, bandas y tribus. Barcelona: Ariel.

Feixa, Carles. (2003). Cidade secreta: os espaços quotidianos dos jovens. Trajectos - Revista de Comunicação, Cultura e Educação, 3, p. I25-I40.

Feixa, Carles \& Nilan, Pam. (2009). Uma juventude global? Identidades híbridas, mundos plurais. Política \& trabalho. Revista de Ciências Sociais, 3I, p. I3-28.

Feixa, Carles \& Nofre, Jordi. (2012). Youth cultures. Sociopedia.isa. Disponível em: <http://www.sagepub.net/isa/ resources/pdf/YouthCultures.pdf $>$. Acesso em $20 \mathrm{dez}$. 2018.

Feixa, Carles \& Porzio, Laura. (2008). Um percurso visual pelas tribos urbanas de Barcelona. In: Pais, José M.; Carvalho, Clara \& Gusmão, Neusa M. (orgs.). O visual e o quotidiano. Lisboa: ICS, p. 87-II3.

Feixa, Carles \& Weissböck, Lara Pires. (2019). Da geração @ a geração blockchain. A juventude na era post digital. Textura, 2I/47, p. 6-3I.

Fernandez-Planells, Ariadna; Figueras-Mas, Mònica \& Feixa, Carles. (2014). Communication among young people in the \#spanishrevolution: uses of online-offline tools to obtain information about the \#acampadabcn. New Media \& Society, 16/8, p. 1287-1308.

Ferreira, Vitor \& Nunes, Cátia. (20I0). Transições para a idade adulta. In: Pais, José M. \& Ferreira, Vitor S. (orgs.). Tempos e transições de vida. Lisboa: ICS, p. 39-68.

Frith, Simon. (1984). The sociology of youth. Lancashire: Causeway Press.

Glass, Pepper G. (2012). Doing scene: identity, space, and the interactional accomplishment of youth culture. Journal of Contemporary Ethnography, 4I/6, p. 695-7i6. 
Goggin, Gerard. (2013). Youth culture and mobiles. Mobile Media \& Communication, I/I, p. 83-88.

Guerreiro, Maria das Dores \& Abrantes, Pedro. (2005). Como tornar-se adulto: processos de transição na modernidade avançada. Revista Brasileira de Ciências Sociais, 20/58, p. I57-I75.

Hall, Tom; Coffey, Amanda \& Williamson, Howard. (I999). Self, space and place:youth identities and citizenship. British Journal of Sociology of Education, 20/4, p. 50I-5I3.

Hall, Stuart. (2003). A identidade cultural na pós-modernidade. Rio de Janeiro: DP\&A.

Hall, Stuart \& Jefferson, Tony (eds.). (I976). Resistance through rituals. London: Hutchinson.

Hargittai, Eszter. (2010). Digital na(t)ives? Variation in internet skills and uses among members of the 'NET generation'. Sociological Inquiry, 80/I, p. 92-II3.

Hargittai, Eszter. (2008). The digital reproduction of inequality. In: Grusky, David (ed.). Social stratification. Boulder: Westview Press, p. 936-944.

Hargittai, Eszter \& Walejko, Gina. (2008). The participation divide: content creation and sharing in the Digital Age. Information, Communication and Society, II/2, p. 239-256. Hebdige, Dick. (1979). Subculture: the meaning of style. London: Methuen.

Hodkinson, Paul. (2004). Translocal connections in Goth scene. In: Bennett, Andy \& Peterson, Richard (orgs.). Music scenes. Local, translocal, and virtual. Nashville: Vanderbilt University Press, p. I3I-I48.

Ito, Mizuko et al. (2008). Living and learning with new media: summary of findings from the Digital Youth Project. Chicago: MacArthur Foundation.

Jenkins, Henry. (2006). Convergence culture. Where old and new media collide. New York: New York University Press.

Lefebvre, Henri. (I99I). O direito à cidade. São Paulo: Moraes.

Lenhart, Amanda et al. (2007). Teens and social media. Washington: Pew Internet/American Life Project.

Ley, David \& Cybriwsky, Roman. (I974). Urban graffiti as 
territorial markers. Annals of the Association of American Geographers, 64/4, p. 49I-505.

Leyshon, Michael; DiGiovanna, Sean \& Holcomb, Briavel. (2013). Mobile technologies and youthful exploration: stimulus or inhibitor? Urban Studies, 50/3, p. 587-605.

Lindgren, Simon; Dhalberg-Grundber, Michael \& Johansson, Anna. (2014). Hybrid media culture: an introduction. In: Lindgren, Simon (ed.). Hybrid media culture sensing place in a world of flows. Abingdon/New York: Routledge, $p$. I-I5.

Livingstone, Sonia. (20II). Internet, children, and youth. In: Consalvo, Mia \& Ess, Charles (orgs.). The handbook of internet studies. Oxford: Blackwell, p. 348-368.

Loader, Brian; Vromen, Ariadne \& Xenos, Michael. (2014). The networked young citizen: social media, political participation and civic engagement. Information, Communication \& Society, I7/2, p. I43-I50.

Lüders, Marika. (20II). Why and how online sociability became part and parcel of teenage life. In: Consalvo, Mia \& Ess, Charles (orgs.). The handbook of internet studies. Oxford: Blackwell Publishing, p. 452-468.

MacLuhan, Marshal. (1994) [1964]. Understanding media: the extensions of man. Massachussets: MIT Press.

Magnani, José G. (2005). Os circuitos dos jovens urbanos. Tempo Social - Revista de Sociologia da USP, I2/2, p. 173-205.

Marcon, Frank. (2013). O kuduro como expressão da juventude em Portugal: estilos de vida e processos de identificação. Sociedade e Estado, 28/I, p. 75-90.

Marcon, Frank; Sedano, Livia \& Raposo, Otávio. (2018). Introdução ao dossiê Juventudes e Músicas Digitais Periféricas. Cadernos de Arte e Antropologia, 7/I, p. 5-I4.

Massey, Doreen. (I998). The spatial construction of youth cultures. In: Skelton, Tracey \& Valentine, Gill (eds.). Cool places: geographies of youth cultures. London: Routledge, $\mathrm{p}$. I22-I30.

Mihailidis, Paul. (20I4). A tethered generation: exploring the role of mobile phones in the daily life of young people. Mobile Media \& Communication, 2/I, p. 58-72.

Molnár, Virág. (2014). Reframing public space through 
digital mobilization: flash mobs and contemporary urban youth culture. Space and Culture, I7/I, p. 43-58.

Muggleton, David \& Weinzierl, Rupert (orgs.). (2003). The post-subcultures reader. New York: Berg.

Muller, Marion. (2008). Visual competence: a new paradigm for studying visuals in the social sciences. Visual Studies, 23/2, p. IOI-IO2.

Pais, José Machado. (2005). Jovens e cidadania. Sociologia, Problemas e Práticas, 49, p. 53-70.

Pais, José Machado. (1993). Culturas juvenis. Lisboa: IN-CM. Pereira, Alexandre Barbosa. (20I6). Visibilidade e escrita de si nos riscos do pixo paulistano, Revista de Ciências Sociais, 47/I, p. 77-IO

Pereira, Alexandre Barbosa. (2012). Quem não é visto não é lembrado": sociabilidade, escrita, visibilidade e memória na São Paulo da pixação. Cadernos de Arte e Antropologia, I, p. 55-69. Disponível em: < https://cadernosaa.revues.org/63I $>$. Acesso em I fevereiro 2016.

Prensky, Mark. (200I). Digital natives, digital immigrants. On the Horizon, 9/5. Disponível em: <http://www.marcprensky.com/writing/Prensky\%20-\%20Digital\%2oNatives, \%20Digital\%20Immigrants\%20-\%20Partr.pdf>. Acesso em I5 maio 2019.

Rabin, Marcela \& Bacich, Lilian. (2018). O protagonismo juvenil na era digital. Revista Juventude e Políticas Públicas, 2 (ed. especial), p. 40-54.

Recuero, Raquel et al. (20I5). Hashtags functions in the protests across Brazil. Sage Open, 5/2, p. I-I4. Disponível em: <http://sgo.sagepub.com/content/5/2/2 I58244 OI5586 o०o>. Acesso em 20 dez. 2018.

Robards, Brady \& Bennett, Andy. (20II). My tribe: postsubcultural manifestations of belonging on social network sites. Sociology, 45/2, p. 303-317.

Robinson, Catherine. (2000). Creating space, creating self: street-frequenting youth in the city and suburbs. Journal of Youth Studies, 3/4, p. 429-443.

Ross, Jeffrey I. (20I8). Reframing urban street culture: towards a dynamic and heuristic process model. City, Culture and Society, I5, p. 7-13. 
Schwartz, Raz \& Halegoua, Germaine. (20I5). The spatial self: location-based identity performance on social media. New media \& Society, I7/Io, p. I643-1660.

Simões, José Alberto. (2010). Entre a rua e a internet. Um estudo sobre o hip-hop português. Lisboa: Imprensa de Ciências Sociais.

Simões, José Alberto \& Campos, Ricardo. (2017). Digital media, subcultural activity and youth participation: the cases of protest rap and graffiti in Portugal. Journal of Youth Studies, 20/I, p. I6-3I.

Siqueira, Holgonsi \& Medeiros, Márcio. (20II). Somos todos ciborgues: aspectos sociopolíticos do desenvolvimento tecnocientífico. Configurações - Revista de Sociologia, 8, p. II-32. Disponível em: <https://journals.openedition. org/configuracoes/882>. Acesso em 5 abr. 2019.

Snyder, Gregory. (2009). Graffiti lives: beyond the tag in New York's urban underground. New York: New York University Press.

Sutko, Daniel M. \& Souza e Silva, Adriana de. (20I I). Location-aware mobile media and urban sociability. New Media \& Society, I3/5, p. 807-823.

Tapscott, Don. (1998). Growing up digital: the rise of the NET generation. New York: MacGraw Hill.

Valentine, Gill; Skelton, Tracey \& Chambers, Deborah. (I998). Cool places: an introduction to youth and youth cultures. In: Skelton, Tracey \& Valentine, Gill (orgs.). Cool places. Geographies of youth cultures. London/New York: Routledge, p. I-32.

Vanden Abeele, Mariek M. P. (20I6a). Mobile lifestyles: conceptualizing heterogeneity in mobile youth culture. New Media \& Society, I8/6, 908-926.

Vanden Abeele, Mariek M. P. (20I6b). Mobile youth culture: a conceptual development. Mobile Media \& Communication, 4/I, 85-Ior.

Williams, J. Patrick. (2006). Authentic identities. Straightedge subculture, music, and the internet. Journal of Contemporary Ethnography, 35/2, p. I73-200.

Willis, Paul. (1990). Commom culture: symbolic work at play in everyday cultures of the young. Milton Keynes: Open University Press. 
Wilson, Brian \& Atkinson, Michael. (2005). Rave and straightedge, the virtual and the real: exploring online and offline experiences in Canadian youth subcultures. Youth \& Society, 36/3, p. 276-3II.

Woodman, Dan \& Leccardi, Carmen. (2015). Time and space in youth studies. In: Wyn, Johanna \& Cahill, Helen (orgs.). Handbook of children and youth studies. Singapore/ Heidelberg/New York/Dordrecht/London: Springer, p. 705722. 
Palavras-chave

Culturas juvenis; culturas de rua; espaço público; mídias digitais.

Keywords

Youth cultures; street cultures; public space; digital media.

\section{JUVENTUDE E CULTURAS DE RUA HÍBRIDAS}

\section{Resumo}

Para a juventude o espaço público urbano corresponde a um campo de sociabilidade e de criatividade, utilizado como palco para o desenvolvimento de práticas que se desenrolam fora da alçada das instituições e do adulto. A generalização da internet e dos dispositivos móveis teve impacto na forma como o espaço é hoje vivido e representado pelos jovens. Aquilo que tradicionalmente era entendido pelas ciências sociais como "culturas de rua juvenis" não pode ser hoje pensado como próprio apenas do espaço físico, posto que possui extensão virtual. Referimos, por isso, culturas de rua híbridas, que navegam entre o mundo offline e online. $\mathrm{O}$ artigo avalia essa matéria partindo de uma revisão da literatura e de dados de diversos projetos de pesquisa desenvolvidos ao longo da última década.

\section{YOUTH AND HYBRID STREET CULTURES}

\section{Abstract}

For young people, urban public space comprises a field of sociability and creativity, used as a stage for the development of a series of practices that unfold outside the competence of the adult world and its institutions. The generalization of the internet and mobile devices has had an impact on how space is lived and represented today by young people. What was traditionally understood by the social sciences as "youth street cultures" cannot be thought of as existing only in physical space, but equally as possessing a virtual extension. We speak, therefore, of "hybrid street cultures," which navigate between the offline and online world. This article assesses the theme based on a review of the literature and the data from diverse research projects developed over the last decade. 